\title{
Review \\ Ethics review: 'Living wills' and intensive care - an overview of the American experience
}

\author{
Andrew RJ Tillyard \\ Specialist Registrar, Intensive Care Department, Royal Cornwall Hospital, Truro TR1 5LJ, UK
}

Corresponding author: Andrew RJ Tillyard, arjtillyard@hotmail.com

Published: 11 July 2007

This article is online at http://ccforum.com/content/11/4/219

(c) 2007 BioMed Central Ltd
Critical Care 2007, 11:219 (doi:10.1186/cc5945)

The 2005 Mental Capacity Act allows a competent person aged over 18 to make an $A D$ that pre-emptively states their treatment preferences or to appoint a lasting power of attorney (LPA) to make decisions for them, if they become incapacitated. There is no set format for an AD (it can be written or verbal) unless it is specifically pertaining to refusing life-sustaining treatment, where it must be written and counter-signed. There is no obligation to seek advice from medical professionals when drawing up an $A D$, and it can be revoked verbally. If valid to the clinical scenario, an $A D$ will override a LPA if one exists. The LPA must act in the patient's best interests, must be registered with the Office of Public Guardian, and the document must be structured in a statutory form that is counter-signed by an independent third party. The LPA can refuse life-sustaining treatment if it is explicitly stated in the patient's draft, is counter-signed and is deemed to be compatible with the patient's 'best interests'. Where disagreement exists between the attending physicians and either the AD or the LPA regarding their validity to the clinical situation, the Court of Protection can arbitrate [6]. Complying with the patient's preferences will in part depend on the difficult 'diagnosis' of futility and the relevance of the clinical scenario to the AD.

The purpose of the present review is to examine the effects ADs have had for critically ill adults. A MedLine and PubMed search was performed using the search terms 'intensive care', 'advance decisions', living wills' and 'surrogates'. Appropriate referenced articles were also included. The bulk of the reviewed literature pertaining to $A D s$ has come from American studies unless specifically stated.

\section{Quality-of-life judgements and advance decisions}

The decision to limit therapy in the ICU can be varied depending on the beliefs and local practice variations of the

$A D=$ advance decision; $I C U=$ intensive care unit; $L P A=$ lasting power of attorney; $Q O L=$ quality of life. 
attending intensivists [7]. Withdrawal is often based on futility or on the perceived prospect that if the patient did survive, it would be with a significantly reduced quality of life (QOL) $[1,7]$. Determining futility is heavily dependent on determining the outcome, but the likelihood of general nonsurvivability from a critical illness is not an objective or precise tool [8]. There is no perfect measure of QOL [9], and neither is there a correlation between the severity of illness and the healthrelated QOL at 6 months: the QOL is not predictable from the clinical information at the time of the acute illness [10]. Finally, despite a reduced functional ability after discharge, the majority of survivors were happy with their QOL and would undergo intensive care again, especially the elderly [10-17]. Establishing the appropriateness of ongoing ICU care based in part on issues such as the resulting QOL may therefore become more similar to the patient's wishes if they have given their reasons for refusing certain medical interventions.

Unfortunately, there is very little clinical evidence to suggest that ADs improve decision-making. One study of patients and doctors given clinical scenarios with and without the presence of an AD suggested that ADs made the physician's decision more compatible with that of the patient [18]. The SUPPORT study of 9,105 seriously ill patients, however, found the $A D$ was associated only with insignificant trends towards improvement in the provision of resuscitation [19]. In the same study, $60 \%$ of surrogates stated that the AD helped only a little or not at all for patients who had an AD and died. These findings may be influenced by the fact that, of the patients with an $A D$, only $12 \%$ completed it with physician involvement, and only $25 \%$ of physicians were aware that the patient had an AD. There is also no requirement for the individual to state their reasons for refusing a medical intervention, which may explain why ADs have been shown to increase conflict between family members and attending physicians [20]. This conflict can be related to the different interpretations that different relatives and physicians have of the patient's $A D$ and the progress and prognosis of the acute illness. Finally, relatives cannot be relied upon to introduce the $A D$ at the onset of a critical illness: sometimes they have used the $A D$ to initiate less invasive support early on and sometimes the AD has not been made known at all [21].

\section{Cost of intensive care provision and advance decisions}

Intensive care is an expensive and limited resource, consuming up to $20 \%$ of the entire hospital budget and $1 \%$ of the nation's gross domestic product [22]. Overall, 25\% of patients that require intensive care die while in the ICU [23]. This is in part due to the aging population, because intensive care is being offered to an older and more unwell group of patients [24]. Patients aged over 65 account for $64.9 \%$ of all cases of sepsis and for greater than $50 \%$ of the ICU bed occupancy $[25,26]$. The World Bank population statistics have shown that the over-65 age group has increased dramatically while the proportion of the older population who remain employed has reduced [27]. In America, the number of patients aged over 85 has increased by 38\% from 1990 to 2000 [28].

If elderly patients with a potential critical illness are questioned about end-of-life decisions, up to $41 \%$ choose to limit certain life-sustaining therapies including cardiopulmonary resuscitation, ventilation and ICU admission [29,30]. Potentially because of this, the majority of studies analysing the financial effect of ADs have shown reduced expenditure [31]. In one study, the average cost of end-of-life care in a university hospital was reduced from $\$ 95,000$ to $\$ 30,000$ [32]. These savings were due to shorter durations of ICU stay and hospital stay rather than due to patients with ADs being provided less ICU therapies [33]. Indeed, these patients received the same number or more interventions than those patients without an $A D$ [2,33-36]. One interpretation of this observation is that patients with an $A D$ are receiving full and active treatment but, once it becomes 'futile', treatment is stopped more quickly out of respect for the patient's wishes. Anecdotally, it is easier to withdraw treatment when the family and staff are in agreement that this is what the patient would have wanted.

\section{Incidence of advance decisions in the intensive care unit}

ADs have existed in the USA for more than 20 years but the number of people who actually have a written $A D$ remains small [5]. The number of ADs in patients with unanticipated critical illness is especially limited, with only $5-11 \%$ of patients having an AD [34,37-39]. In a separate American study of patients with relapsed haematological malignancy, the percentage of patients with an $A D$ only rose to $32 \%$ despite the patient having had more time than most people to consider their own mortality and the possibility of requiring critical care [33]. It can therefore be assumed that the number of ADs in those patients with a sudden unexpected, critical illness will be very limited in England and Wales for many years past 2007 .

\section{How will the lasting power of attorney be assessed?}

The predetermined LPA or surrogate can make decisions on an incompetent patient's behalf that can include the ability to refuse life-sustaining treatment if the document appointing the LPA explicitly acknowledges this. Because the 2005 Mental Capacity Act is statutory law, it will become a criminal offence to ignore the AD or the LPA. This leaves the potential for the physician to be found guilty of the offence of 'Battery' if they do not comply.

The SUPPORT study and the HELP study of elderly and acutely ill inpatients found that, of 1,041 patients who had expressed a clear preference regarding resuscitation, more than $70 \%$ said that if they did become incapacitated they 
would want the family and physician to make the resuscitation decisions rather than having their own AD followed [40]. Yet the level of agreement between the surrogate's decision and the patient's preference in real and hypothetical seriously ill scenarios was only $68 \%$ in a meta-analysis of 16 studies analysing this outcome [41]. To highlight this observation, in an Australian study $83 \%$ of patients did not want invasive treatment and $76 \%$ of the surrogates agreed invasive treatment was inappropriate, but all surrogates initiated it [42]. Finally, discussing the advance decision with the surrogate and the patient does not improve the surrogate's accuracy. In a study of 717 seriously ill patients and their surrogates, 54\% were assigned to the intervention group, which included discussions regarding the prognosis, treatment, resuscitation and ADs, but there was no significant improvement in decision-making on reassessment [43]. These statistics lend weight to the value and importance placed on a surrogate by the patient, but questions their accuracy and detracts from the value of the $A D$ in the first place.

There are other significant practical problems regarding how the LPA will be involved in the decision-making process in the ICU. How much needs to be discussed and documented: routine therapy such as fluids or only the more invasive medical procedures? Secondly, the LPA is expected to make decisions in the best interests of the patient. How will their decision-making abilities and decisions be judged to be in the best interests of the patient? In America, if there is doubt or disagreement between staff and the LPA, a second opinion is recommended, followed by an ethics consultation, culminating with legal advice if still unresolved [44]. A similar process including an Independent Mental Capacity Advisor and the Court of Protection will occur in England and Wales.

\section{Interpreting advance decisions in the intensive care unit}

The majority of ADs that have been encountered in the intensive care setting are general in nature regarding the limitation of treatment, rather than specific to a particular critical illness $[45,46]$. The acutely ill patient in critical care does not always have a specific diagnosis initially, which leads to uncertainties regarding the appropriate treatment, its probable efficacy and the prognosis. These factors will combine to significantly increase the difficulty as regards when the $A D$ should be implemented, its true applicability to the clinical situation and how it is interpreted.

Following an $A D$ and withholding treatment may not always appear to be in the person's 'best interests'. A patient's AD, however, needs only conform to their values rather than their 'best medical interests' - the Jehovah's Witness being the classic example. Ignoring the AD because it is thought the reasoning behind it was poor is potentially risky: 'professionals should start from the assumption that a person who has made an AD had capacity to make it' [6].
In a previous case bought before the English Courts in 1994, irrational thought did not equal incompetence when refusing treatment [47]. The case involved a schizophrenic man who was refusing to have his gangrenous toe amputated because he did not consider life without his toe acceptable. The attending surgeons tried to argue that this was irrational, and therefore the patient lacked competence, and were seeking permission to proceed with the amputation. The courts ruled in the patient's favour, however, because he fulfilled the requirements of competence: he had been given and retained the information, he understood and believed the gravity of his decision, and he evaluated the information in relation to his self. It can be seen that a great concern with the AD is not the $A D$ itself, but that it becomes medico-legally easier to follow the $A D$ rather than to strive to keep the patient alive.

\section{Suicide, intensive care and advance decisions} The 2005 Mental Capacity Act expressly rejects an AD that is drawn up to facilitate suicide. A young person completing an $A D$ and subsequently taking a paracetamol overdose to ensure active treatment is withheld is therefore not legally binding: this would be euthanasia by omission because death is the intended outcome and not providing treatment facilitates this outcome.

For many people, however, there are situations where one's own life would not be deemed worthwhile because one's resultant QOL would fall below their own subjective threshold of acceptability. Although made autonomously, it has been said that to knowingly refuse certain treatment because of the probable residual $\mathrm{QOL}$, with the inevitable consequence being death, is morally no different to the decision to actively end one's life because of one's QOL [48]. It is argued that this legalises euthanasia by the back door: 'pre-emptive euthanasia by omission'. The morally correct action of limiting life-sustaining treatment depends on futility and burden. Senior Catholic ethicists have gone as far as to state that self-destructive choices do not necessarily warrant respect: the choices made 'have to be consistent with the fundamental dignity of both the chooser and others' [48]. The counter argument to this is that, because death is not the intended outcome, an AD is not euthanasia by omission: a treatment that provides/maintains an acceptable QOL is wanted, and if therapy cannot achieve this then it is refused.

\section{Conclusion}

The present review has shown that there is very little evidence regarding the effect that ADs actually have on the treatment of acutely ill patients in the ICU. The potential benefit of an $A D$ in the ICU includes that it will probably reduce the cost of ICU care, and this will not be secondary to a restriction of therapy offered. The review suggests the AD will not invariably produce treatment that is consistent with the patient's wishes, however, and therefore it cannot be assumed to always facilitate harmonious decision-making at the end of life or to maintain an incapacitated patient's 
autonomy. The present review also highlights the problem of how different people interpret and use an $A D$, and introduces the difficulty of where an $A D$ should be kept if relatives cannot always be relied upon to make them available. A great concern is that it may become easier to follow an AD that will be very unlikely to result in legal action. It will be the far bolder physician who is prepared to interpret and ignore an AD.

\section{Competing interests}

The author declares that they have no competing interests.

\section{References}

1. Wunsch H, Harrison DA, Harvey S, Rowan K: End-of-life decisions: a cohort study of the withdrawal of all active treatment in intensive care units in the United Kingdom. Intensive Care Med 2005, 6:823-831

2. Teno JM, Lynne J, Phillips RS, Murphy D, Youngner SJ, Bellamy P, Connors AF, Desbiens NA, Fulkerson W, Knaus WA: Do formal advance directives affect resuscitation decisions and the use of resources for seriously ill patients? SUPPORT Investigators. Study to Understand Prognoses and Preferences for Outcomes and Risks of Treatments. J Clin Ethics 1994, 5:23-30.

3. Azoulay E, Pochard F, Kentish-Barnes N, and the FAMIREA Study Group: Risk of post-traumatic stress symptoms in family members of intensive care unit patients. Am J Respir Crit Care Med 2005, 171:987-994.

4. Emmanuel EJ, Emmanuel LL: Proxy decision making for incompetent patients: an ethical and empirical analysis. JAMA 1992, 267:2067-2071.

5. Doukas D: Advance directives in patient care: if you ask, they will tell you. Am Family Phys 1999, 59:530-533.

6. UK Department of Health: Mental Capacity Act 2005 Code of Practice 2007 [www.opsi.gov.uk/acts/en2005/ukpgaen_20050009_ en_cop.pdf]

7. Predergast TJ, Claessens MT, Luce JM: A national survey of end-of-life care for critically ill patients. Am J Respir Crit Care Med 1998, 158:1163-1167.

8. Bernat JL: Medical futility. Definition, determination, and disputes in critical care. Neurocrit Care 2005, 2:198-205.

9. Wu A: Long term outcomes in survivors from critical illness. Anaesthesia 2004, 59:1049-1052.

10. Maynard SE, Whittle J, Chelluri L, Arnold R: Quality of life and dialysis decisions in critically ill patients with acute renal failure. Intensive Care Med 2003, 29:1589-1593.

11. Ridley S, Biggam M, Stone P: A cost-utility analysis of intensive therapy. II: Quality of life in survivors. Anaesthesia 1994, 49:192-196.

12. Konopad E, Noseworthy TW, Johnstone R, Schustack A, Grace $M$ : Quality of life measures before and one year after admission to an intensive care unit. Crit Care Med 1995, 23:16531659.

13. Danis M, Patrick DL, Southerland LI, Green ML: Patients' and families' preferences for medical intensive care. JAMA 1988, 260:797-802

14. Angus DC, Carlet J, and the 2002 Brussels Roundtable Participants: Surviving intensive care: a report from the 2002 Brussels Roundtable. Intensive Care Med 2003, 29:368-377.

15. Montuclard L Garrouste-Orgeas M, Timsit JF, Misset B, De Jonghe B, Carlet J: Outcome, functional autonomy, and quality of life of elderly patients with a long-term intensive care unit stay. Crit Care Med 2000, 28:3389-3395.

16. Chelluri L Im KA, Belle SH, Schulz R, Rotondi AJ, Donahoe MP, Sirio CA, Mendelsohn AB, Pinsky MR: Long-term mortality and quality of life after prolonged mechanical ventilation. Crit Care Med 2004, 32:61-69.

17. Frick S, Uehlinger DE, Zuercher Zenklusen RM: Medical futility: predicting outcome of intensive care unit patients by nurses and doctors - a prospective comparitive study. Crit Care Med 2003, 31:456-461.

18. Coppola KM, Ditto PH, Danks JH, Smuker WD: Accuracy of primary care and hospital-based physicians' predictions of elderly outpatients' treatment preferences with and without advance directives. Arch Internal Med 2001, 161:431-440.
19. Teno J, Lynn J, Wenger N, Phillips RS, Murphy DP, Connors AF, Desbiens N, Fulkerson W, Bellamy $P$, Knaus $W$, for the SUPPORT Investigators: Advance directives for the seriously ill hospitalised patients: effectiveness with the patient selfdetermination act and the SUPPORT intervention. J Am Geriatr Soc 1997, 45:500-507.

20. Ewer MS, Taubet JK: Advance directives in the intensive care unit of a tertiary cancer centre. Cancer 1995, 76:1268-1274.

21. Kavic SM, Atweh N, Possenti PP, Ivy ME: The role of advance directives and family in end-of-life decisions in critical care units. Conn Med 2003, 67:531-534.

22. Polderman $\mathrm{KH}$, Metnitz PGH: Using risk adjustment systems in the ICU: avoid scoring an 'own goal'. Intensive Care Med 2005, 31:1471-1473.

23. Audit Commission: Critical to Success. London; 1999 [http:// www.audit-commission.gov.uk/Products/NATIONAL-REPORT/ 40B50F26-ED9F-4317-A056-042B31AEA454/ CriticalToSuccess.pdf].

24. McCarthy JT: Prognosis of patients with acute renal failure in the intensive-care unit: a tale of two eras. Mayo Clin Proc 1996, 71:117-126.

25. Martin GS, Mannino DM, Moss M: The effect of age on the development and outcome of sepsis. Crit Care Med 2006, 34: $15-21$.

26. Angus DC, Kelley MA, Schmitz RJ, White A, Popovich J, Committee on manpower for pulmonary and critical care societies (COMPACCS): Caring for the critically ill patient. Current and projected workforce requirements for care of the critically ill and patients with pulmonary disease: can we meet the requirements of an aging population? JAMA 2000, 284:27622770.

27. National Statistics Online [http://www.statistics.gov.uk/cci/ nugget.asp?id=949]

28. Hetzel L, Smith A: The 65 years and over population: 2000. Census 2000 brief [http://www.census.gov/prod/2001pubs/ c2kbr01-10.pdf]

29. Reilly BM, Magnussen CR, Ross J, Ash J, Papa L, Wagner M: Can we talk? Inpatient discussions about advance directives in a community hospital. Attending physicians' attitudes, their inpatients' wishes, and reported experience. Arch Internal Med 1994, 154:2299-2308.

30. Essebag V, Cantarovich M, Crelinsten G: Routine advance directive and organ donation questioning on admission to hospital. Ann R Coll Phys Surg Canada 2002, 35:225-231.

31. Weeks WB, Kofoed LL, Wallace AE, Welch HG: Advance directives and the cost of terminal hospitalization. Arch Internal Med 1994, 154:2077-2083.

32. Chambers CV, Diamond JJ, Perkel RL, Lasch LA: Relationship of advance directives to hospital charges in a Medicare population. Arch Internal Med 1994, 154:541-547.

33. Kish Wallace S, Martin CG, Shaw AD, Price KJ: Influence of an advance directive on the initiation of life support technology in critically ill cancer patients. Crit Care Med 2001, 29:22942298.

34. Goodman MD, Tarnoff M, Slotman GJ: Effect of advance directives on the management of elderly critically ill patients. Crit Care Med 1998, 26:701-704.

35. Danis M, Southerland LI, Garrett JM, Smith JL, Hielema F, Pickard CG, Egner DM, Patrick DL: A prospective study of advance directives for life-sustaining care. $N$ Engl $J$ Med 1991, 324: 882-888.

36. Schneiderman $L$, Kronick R, Kaplan RN, Anderson JP, Langer $\mathrm{RD}$ : Effects of offering advance directives on medical treatments and costs. Ann Internal Med 1992, 117:599-606.

37. Faber-Langendoen $\mathrm{K}: \mathbf{A}$ multi-institutional study of care given to patients dying in hospitals. Ethical and practice implications. Arch Internal Med 1996, 156:2130-2136.

38. Karlawish $\mathrm{JH}$, Hall JB: Managing death and dying in the intensive care unit. Am J Respir Crit Care Med 1997, 155:1-2.

39. Johnson RF, Baranowski-Birkmeier T, O'Donnell JB: Advance directives in the medical intensive care unit of a community teaching hospital. Chest 1995, 107:752-756.

40. Puchalski C, Zhong Z, Jacobs MM, Fox E, Lynne J, Harrold J, Galanos A, Phillips RS, Califf R, Teno JM: Patients who want their family and physician to make resuscitation decisions for them: observations from SUPPORT and HELP. J Am Geriatr Soc 2000, 48:S84-S90. 
41. Shalowitz DI, Garrett-Meyer E, Wendler D: The accuracy of surrogate decision makers. A systematic review. Arch Internal Med 2006, 166:493-497.

42. Corke CF, Lavery JF, Gibson AM: Choosing life support for suddenly severely ill relatives. Crit Care Resusc 2005, 7:81-86.

43. Marbella AM, Desbiens NA, Mueller-Rizner N, Layde PM: Surrogates' agreement with patients' resuscitation preferences: effect of age, relationship, and SUPPORT intervention. J Crit Care 1998, 13:140-145.

44. Bramstedt KA: Questioning the decision-making capacity of surrogates. Internal Med J 2003, 33:257-259.

45. Block AJ: Living wills are overrated. Chest 1993, 104:16451646.

46. Emmanuel LL: Does the DNR order need life-sustaining intervention? Time for comprehensive advance directives. $\mathrm{Am} J$ Med 1989, 86:87-90.

47. Re C (Adult: Refusal of Medical Treatment) [1994] All ER 819

48. Gormally L: Legislating for advance refusals of treatment: what is at issue? [http://www.linacre.org/advdirec.html] 